HORST BREDEKAMP

\title{
VOM BERLINER SCHLOSS ZUM HUMBOLDT FORUM: EIN PARADIGMA DEUTSCHER KONFLIKTGESCHICHTE
}

Sehr geehrte Damen und Herren,

aus Anlass des 100. Jubiläums des Posener kunsthistorischen Institutes zu sprechen, ist mir eine große Ehre. Der Begründer dieses Institutes, Szczęsny Dettloff, gehört zu den herausragenden Gelehrten der Kunstgeschichte des letzten Jahrhunderts. Stark an der italienischen Renaissance und der regionalen Kunstgeschichte als der unmittelbaren Basis orientiert, ist er in der deutschsprachigen Kunstgeschichte als Fachmann für das Mittelalter und die nördliche Renaissance, und hier insbesondere für Veit Stoß, eine markante Gestalt geblieben. Er hat auch bei Heinrich Wölfflin, wohl noch in dessen Berliner Jahren, studiert. Die unselige Zeit, in der die Universität Posen 1941 in die deutsche Reichsuniversität umgewandelt wurde, hat zumindest einen versöhnlichen Punkt darin, dass Dettloff durch die Intervention von KarlHeinz Clasen im Jahr 1939 aus dem Internierungslager befreit wurde. Durch seine Bindung an die Wiener Schule, und insbesondere an Max Dvořák, hatte Dettloff eine starke ideengeschichtliche Prägung, die sich im Posener Institut bis heute fortgesetzt hat. Aus dem Rückblick höchst bemerkenswert sind die Versuche des Posener Institutes, die zeitgenössische französische Philosophie wie auch die Reformbewegung der westdeutschen Kunstgeschichte zu reflektieren. Die Einladung an meinen akademischen Lehrer Martin Warnke an das Posener Institut im Jahr 1973, mitten im Kalten Krieg, war ein Ereignis, dessen Protokoll ein Teil der Wissenschaftsgeschichte geworden ist. Seither war ich lose mit Adam Labuda bekannt, und es war ein glücklicher Zufall, dass wir im selben Jahr 1992 an das Wissenschaftskolleg zu Berlin berufen wurden - und dort eine sehr starke Tischtennismannschaft bildeten. Dies hat uns bis heute verbunden.

Adam Labuda hat in einem seiner Artikel zur Wissenschaftsgeschichte bedauernd darauf verwiesen, dass sich manche Begabungen der Kunstgeschichte vornehmlich nach Süden und Westen gewendet hätten, und damit 
war auch ich gemeint. Ich kann mir aber zusprechen, dass ich, als ich 1993 Direktor am kunstgeschichtlichen Institut der Humboldt-Universität wurde, alles daran gesetzt habe, gegen teils großen Widerstand die Professur für mittel- und osteuropäische Kunstgeschichte zu bewahren. Es war ein Glück, dass es gelang, Adam Labuda mit der Ausfüllung dieser Professur an der Humboldt-Universität begrüßen zu können. Hierdurch gab es enge Kontakte nach Posen, weitere Kollegen gestärkt wurden, und insbesondere durch den viel zu früh verstorbenen Piotr Piotrowski, der mehrere Semester an der Humboldt-Universität gelehrt hat, und den die Kollegen und auch die Studenten in seiner mitreißenden Art sehr geschätzt haben. In Rahmen der bewährten Kontakte zwischen dem Posener und dem Berliner Institut hat mich Piotr
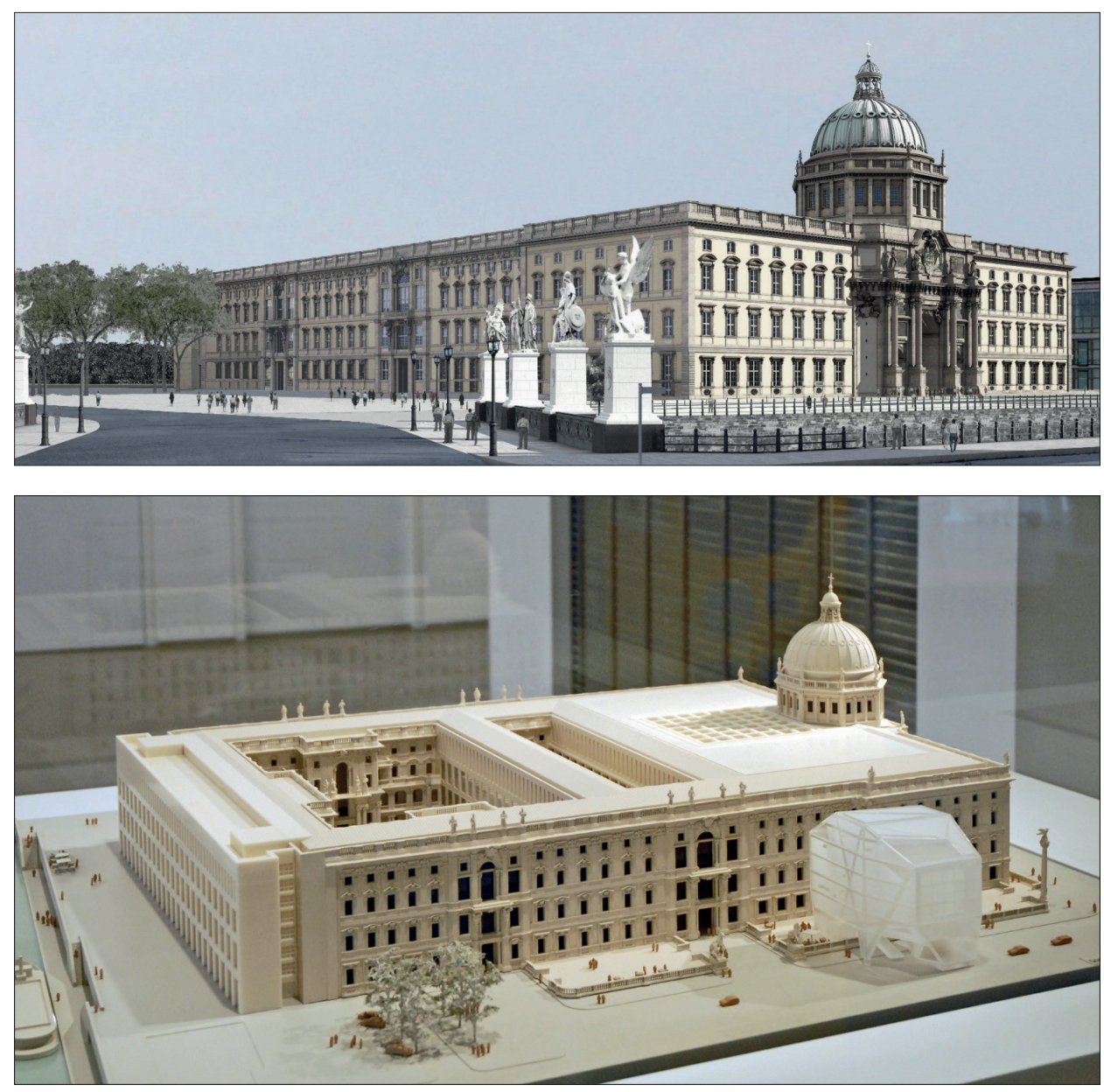

1. Frank Stella, Modell des Berliner Schlosses/Humboldt Forums 
Korduba gebeten, heute zu Ihnen zu sprechen. Es war sein Wunsch, dass ich meinen Vortrag über das Berliner Schloss und jenes Humboldt Forum halte, das ich als einer der Gründungsintendanz für drei Jahre aufzubauen versucht habe.

Das Humboldt Forum hat bereits vor seiner Eröffnung eine Diskussion ausgelöst, die weit über Berlin, über die Bundesrepublik Deutschland und auch über Europa hinaus gegangen ist (Abb. 1 A-B). Dieses Projekt wird im guten wie im negativen Sinn als ein Spezialfall genommen, in dem sich allgemeine Bewertungen der Geschichte mit Fragen der Gestaltung von Zukunft bündeln. Es ist nicht ausgemacht, ob es sich als ein Modell oder ein Unfall der Geschichte erweisen wird, und diese Frage wird möglicherweise aus Ihrer Geschichtserfahrung anders eingeschätzt werden als sie sich mir darbietet. Aber ich hoffe, die nötige Distanz aufzubringen, um Ihnen einen Begriff von der Problematik, welche möglicherweise nicht allein Berlin betrifft, zu geben. Ich werde in insgesamt 10 Schritten vorgehen. Der erste lautet: die römische Perspektive.

\section{DIE RÖMISCHE PERSPEKTIVE}

Mit seiner Mischung aus Formen der Spätgotik und der Renaissance hätte das Berliner Schloss um 1670 kaum ein überregionales Aufsehen erregen können. Seine Eigentümer, die Hohenzollern, verfügten über das Kurfürstentum Brandenburg-Preußen, das zwar einen gewissen Einfluss besaß, mit den europäischen Königreichen aber nicht zu vergleichen war. Getrieben vom Ehrgeiz, auch Preußen die Königswürde zu verleihen, vollzog Kurfürst Friedrich III. den Krönungsakt außerhalb des preußischen Staatsgebietes in Königsberg aus eigener Hand, um die Anmaßung dieses Schrittes gegenüber den europäischen Potentaten zu mindern. Angesichts des beschriebenen Defizits seiner Legitimation setzte er als König Friedrich I. alles daran, durch ein erneuertes Stadtschloss mit dem Anspruchsniveau der europäischen Großmächte gleichzuziehen. Er bezog sich auf Rom, um von der politischen Ikonologie der caput mundi profitieren zu können. Sein persönliches Interesse war keineswegs aufgesetzt; vielmehr gehörte er zum Kreis der Gelehrten, welche die Antike mit beträchtlichem persönlichen und finanziellen Einsatz zu erforschen suchten. Er stellte großzügige Mittel für den Ankauf von Münzen und Medaillen sowie Publikationen zur Verfügung.

Der Akteur der Umwandlung des Schlosses von einem spätgotischen in einen zeitgenössischen barocken Bau war der um 1660 wohl in Danzig geborene Andreas Schlüter (Abb. 2). Ausbildung und erste Werke in seiner Ge- 


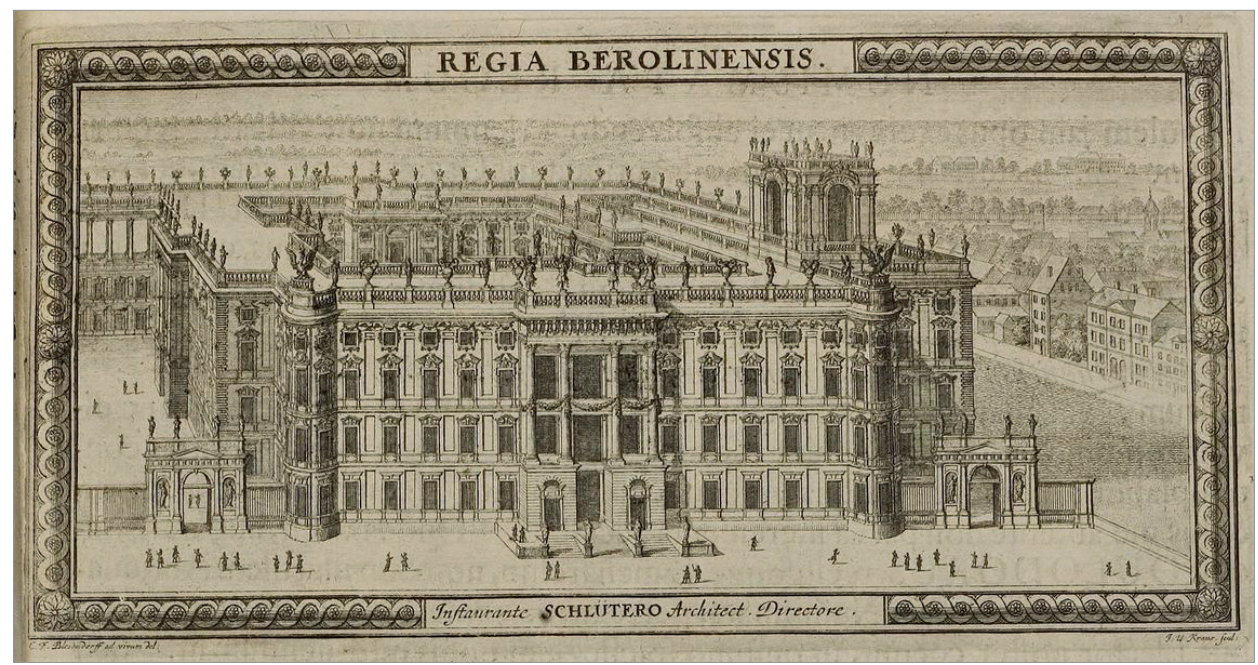

2. Das Berliner Stadtschloss, Kupferstich, 1696-1701

burtsstadt sind zunächst über seine Skulpturen fassbar, die allerdings bislang allein durch Zuschreibungen identifiziert werden konnten. Hierzu gehören die Stuckarbeiten der Erdteile, hier der afrikanische Kontinent, im Haus Langer Markt 7/8 (zerstört), der durch den spielerischen Versuch von Putten charakterisiert ist, einen Löwen zu bändigen. Zugeschrieben sind auch jene Putten, die im Schloss König Jans III. Sobieski in Wilanów die vier Elemente, hier das Wasser, symbolisieren. Dokumentarisch belegt ist dann Schlüters Beteiligung an der Ausschmückung des Warschauer Palais Krasiński im Jahr 1689 mit seinen Szenen aus der republikanischen Zeit Roms. Gesichert sind die Grabmäler für den Vater und den Onkel des Königs in Żółkiew in den Jahren 1692-94, gefertigt aus schwarzem Marmor und den Assistenzfiguren vermutlich der Stärke, Gerechtigkeit sowie Tugend und Wahrheit und jeweils der Fama über der Urne. Diese Grabmäler gehörten neben vermutlich weiteren Werken zu den Ausweisen, die ihm im Jahr 1694 in Berlin die Anstellung als Schlossbaudirektor fand. Bei allem, was jetzt folgt, ist immer zu bedenken, dass es in Gestalt von Andreas Schlüter ein polnischer Hofkünstler war, der das Berliner Schloss erreichtet hat.

Bevor Schlüter sein Projekt begann, verbrachte er mehrere Monate in Italien, und so auch in Rom, um sich den nötigen Horizont zu verschaffen, der Berlin aus der regionalen Formenwelt herausheben sollte. Das unmittelbare Vorbild für den Entwurf des Berliner Schlosses stellte Paolo Marucellis römischer, nahe der Piazza Navona gelegene Palazzo Madama dar (Abb. 3, 4). Es ist, als hätte Schlüter diesen dreieinhalb Stockwerke aufweisenden Palast in Berlin 


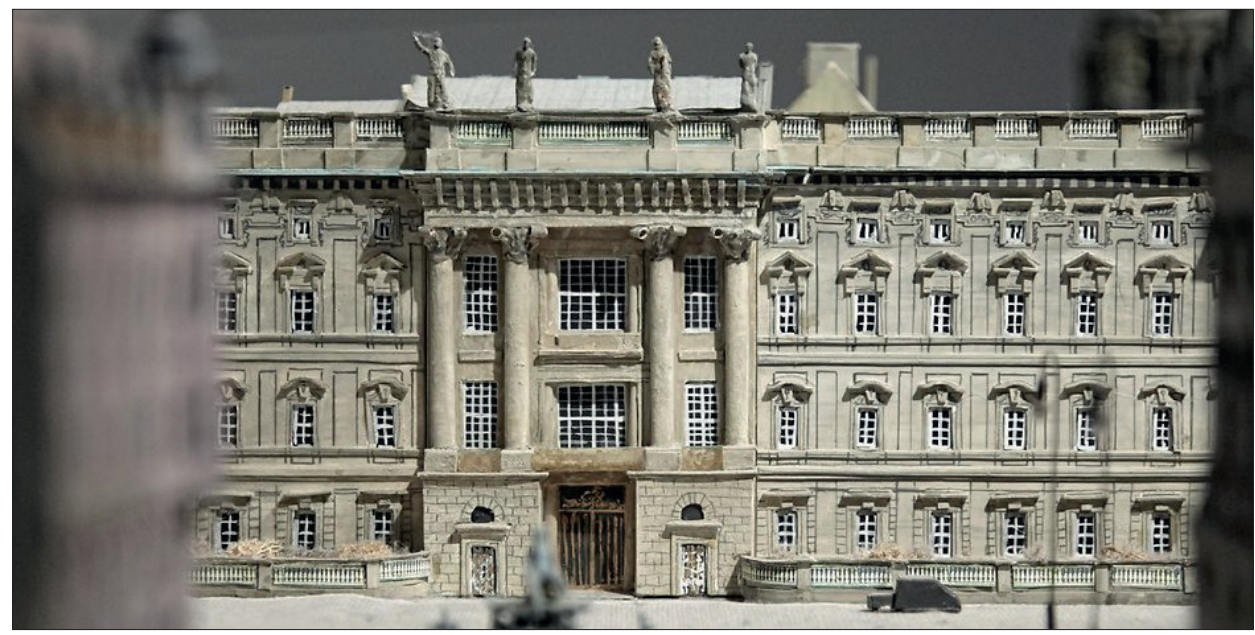

3. Das Berliner Stadtschloss, Fassadenausschnitt

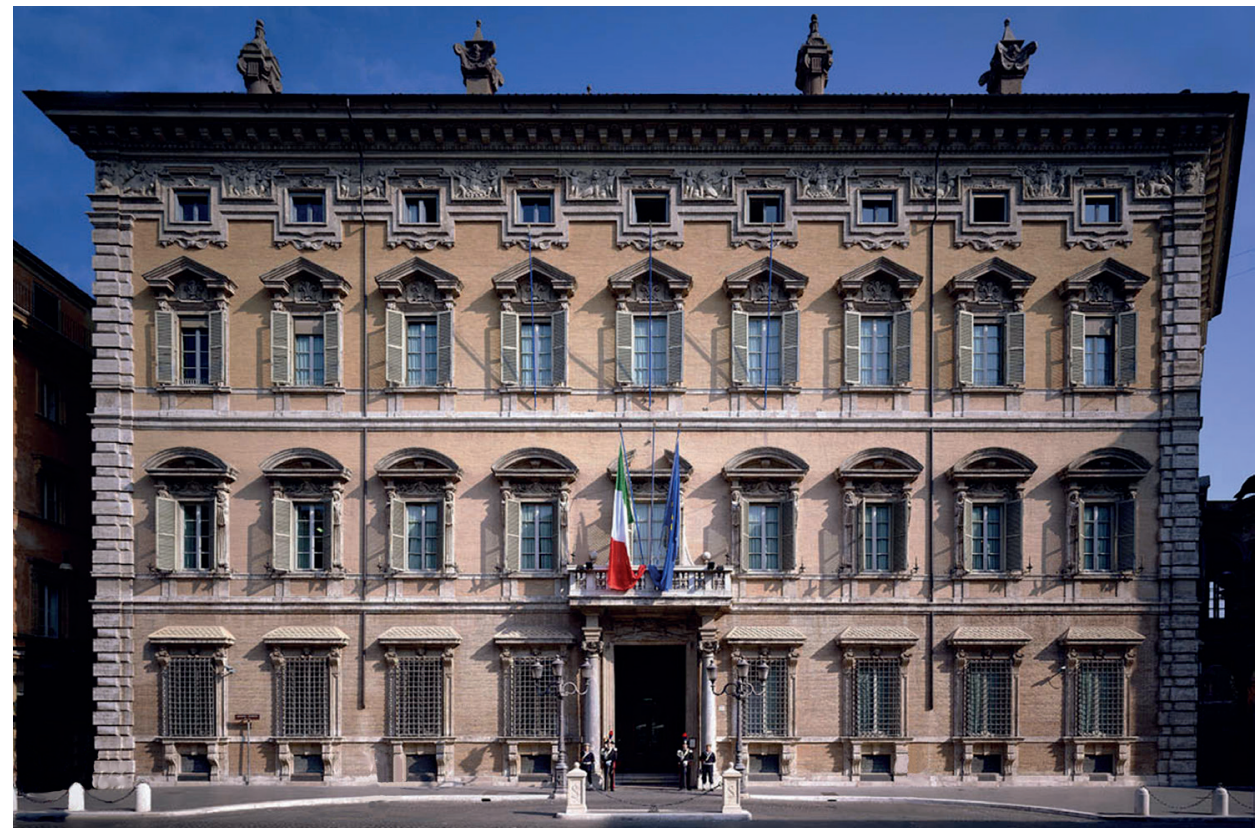

4. Paolo Marucelli, Palazzo Madama, Rom, 1637-1642

schlicht weitergebaut. Selbst die Fensterformen sind bis auf den Unterschied der Kreissegmentformen im ersten Stockwerk identisch. Auch die ungewöhnliche Durchstoßung des Gesimses mittels der Mezzaninfenster, die ein plastisches Element in die Strenge der Architektur bringt, ist übernommen. Ein ein- 
ziger motivischer Unterschied liegt darin, dass in den zwischen den Fenstern über dem Gesims angebrachten Figurenfeldern in Berlin im Gegensatz zum Palazzo Madama nicht etwa spielende Putti, sondern Adler angebracht sind, die sowohl auf Jupiter wie auch Preußen verweisen. Die mächtigen Säulen des großen Treppenhauses tragen über den Kämpfern und dem ausladenden Gesims nichts außer den Figuren des Obergeschosses. Sie dürften von den Peristylsäulen des Nervaforums inspiriert sein. Im Risalit des Großen Treppenhauses übernehmen diese antiken römischen Elemente eine eigene Funktion als autonome Darstellung ihrer selbst: Symbole ihrer Eigenform.

Die durch Schlüters Nachfolger Eosander von 1708 an vollzogene Erweiterung des Schlüterschen Baues nach Westen hat dem Berliner Schloss die abschließende Gestalt vermittelt (Abb. 5). Das vielleicht markanteste

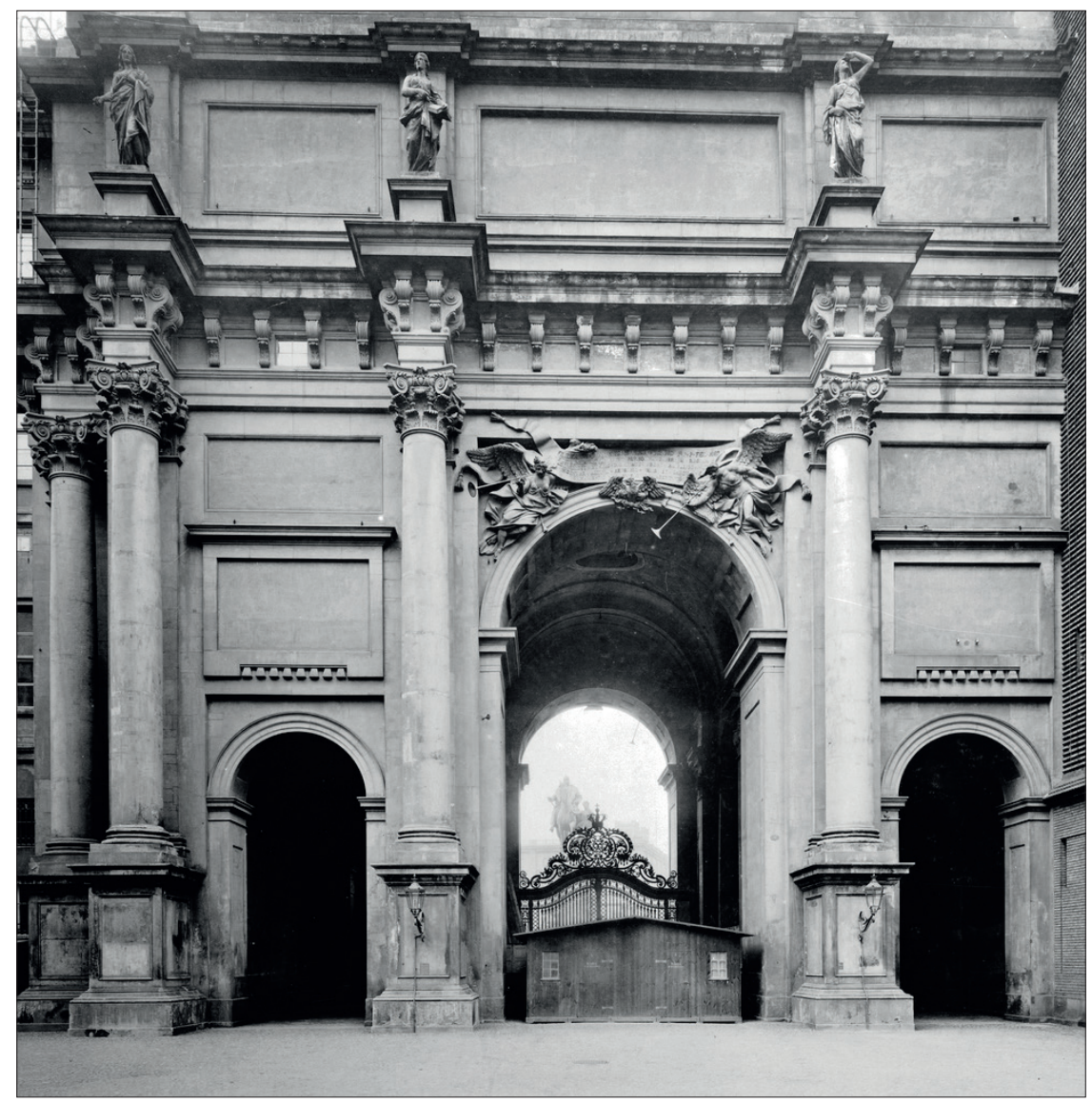

5. Johann Friedrich Eosander, Berliner Stadtschloss, Hoffassade von Portal III, $1708-1716$ 
Motiv zitierte in Form des nach Westen gerichteten Portals III erneut die römische Antike nach Berlin. Außen- wie Innenseite variieren mit dem Konstantins- und im Jahr 203 errichteten Septimius-Severus-Bogen zwei Triumphbögen des Forum Romanum (Abb. 6). Ein Vergleich des Innenportals von Eosander mit dem Septimius-Severus-Bogens vom römischen Forum Romanum kann verdeutlichen, wie getreu auch hier Rom nach Berlin transferiert wurde. Der Eindruck ist überwältigend, aber auch eindimensional cäsarisch. Schlüters Formen zogen dagegen eine eigenwillige Summe der Bau- und Bildgeschichte Roms von der Antike über die Renaissance bis zum zeitgenössischen Barock. Sie fügen die Anregungen nicht etwa kompilatorisch zusammen, sondern dramatisieren sie, um die Kraftlinien der Architektur stärker herauszuarbeiten und einen eigenen, plastischen Stil zu entwickeln: ein mediterranes Theater der Plastizität und der inneren Spannung und Lebendigkeit.

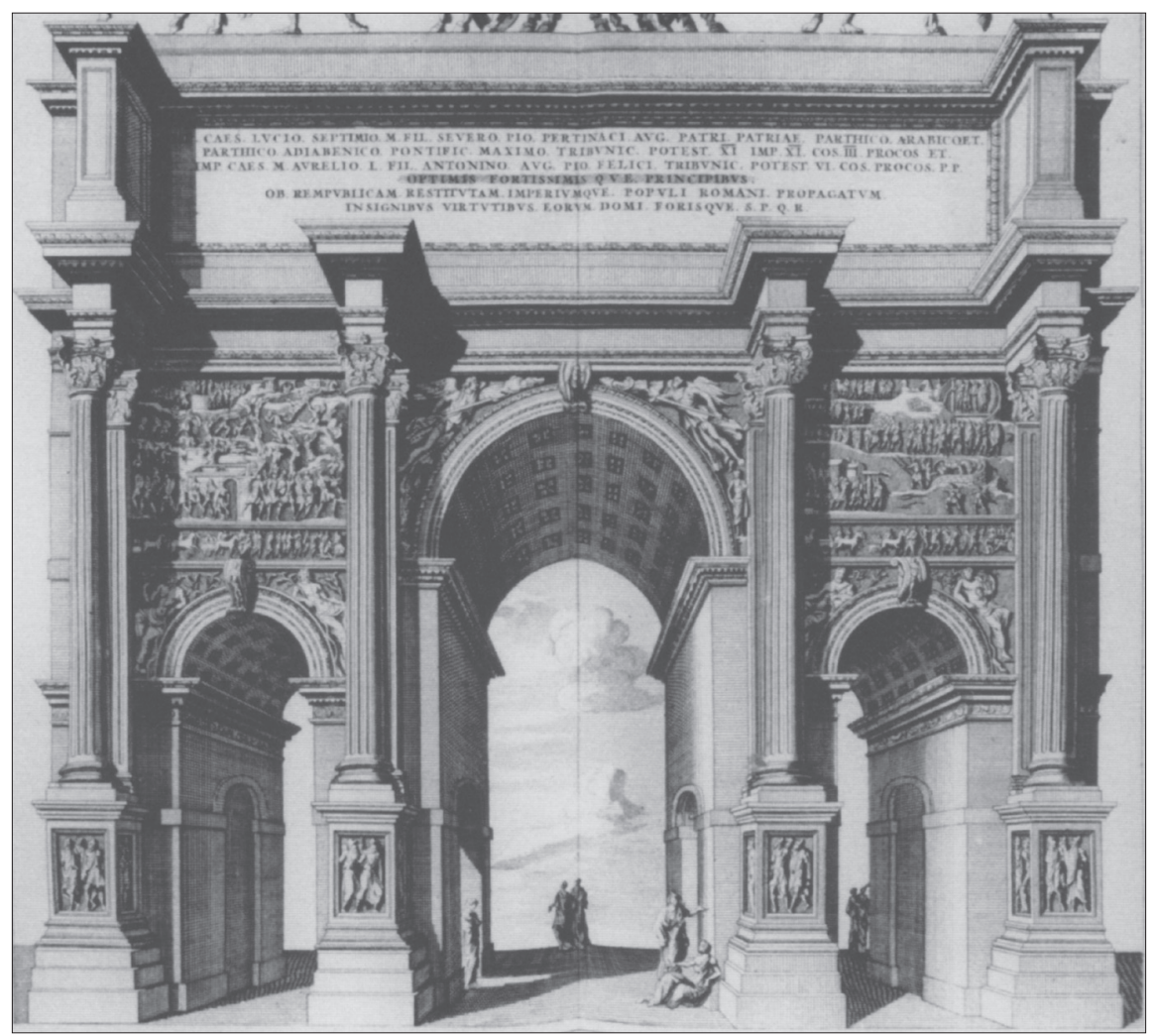

6. Septimius-Severus-Bogen, Rom, 203 n. Chr., Radierung von 1694-1699 


\section{DIE KUNSTKAMMER ALS AKADEMISCHES MUSEUM}

So rigoros das Äußere des Schlosses verwandelt wurde, so stark blieb es der Kontinuität seiner inneren Bestimmung verpflichtet, Residenz des Königshauses zu sein, nicht minder aber eine öffentliche Bestimmung zu haben: durch Gerichte, Finanzämter, Banken, Verkaufszeilen, eine Bibliothek und eine Kunstkammer, die zumindest den Spezialisten und den interessierten Laien offen stand. Über Generationen angewachsen, ging sie im Dreißigiährigen Krieg unter, wurde danach aber so erfolgreich neu aufgebaut, dass sie eine der Anregungen für Gottfried Wilhelm Leibniz bot, die Berliner Akademie der Wissenschaften, die er im Jahr 1700 zu begründen half, als ein „Theater der Natur und Kunst" zu begreifen. Die Kunstkammer sollte der Forschung zur Verfügung stehen. Als ein Weltmuseum umfasste sie sowohl Objekte der Natur wie auch Instrumente der Forschung und schließlich Kunstwerke. Die Betreuung dieser Sammlung schwankte zwischen Sorgfalt und Nachlässigkeit, aber ihr umfassender Anspruch machte sie Hundert Jahre später, um 1800, in besonderer Weise interessant. Denn zu dieser Zeit wurde die Kunstkammer der Akademie der Wissenschaften unterstellt, und es waren insbesondere Alexander und Wilhelm von Humboldt, die sich für diese einsetzen. Es war ein Sonderfall der Museumsgeschichte, dass zu einem Zeitpunkt, zu dem sich überall in Europa die Sammlungen spezialisierten und sowohl in Gemäldegalerien und Kunstmuseen sowie technische Museen und Museen der Naturkunde aufgeteilt wurden, Berlin an jenem Mikrokosmos der gesamten Welt festhielt, den die Kunstkammer darstellte. Hiervon profitierte zunächst die Universität. Im Jahr 1809 bewirkte Wilhelm von Humboldt, dass die neu zu gründende Berliner Universität, die dem am Boden liegenden Gemeinwesen wenigstens geistig zu einer neuen Größe verhelfen sollte, mit jenen Sammlungen der Naturforschung und der Medizin ausgestattet wurde, die sich in der Kunstkammer des Berliner Schlosses befanden. Dies geschah im Jahr 1810, als das an der Prachtstraße Unter den Linden gelegene große Palais des Bruders von Friedrich dem Großen der Universität übergeben wurde (Abb. 7). Die Sammlungen, die in diesem großformatigen Gebäude untergebracht wurden, füllten es so gut wie vom Dach bis zum Boden aus. Als der König die Universität im Jahr 1820 besuchte, trug er in das Ehrenbuch ein: „Ein wunderbares neues Museum!“

Auf diese Weise war die Universität zu einer Tochter des Berliner Schlosses geworden. Die bis zum Jahr 1933 andauernde Erfolgsgeschichte der Berliner Universität wird auf die von Wilhelm von Humboldt definierte Freiheit von Forschung und Lehre zurückgeführt. Der zweite Grund wird jedoch zumeist vergessen: Als Erbin großer Teile der Sammlungen des Schlosses war 


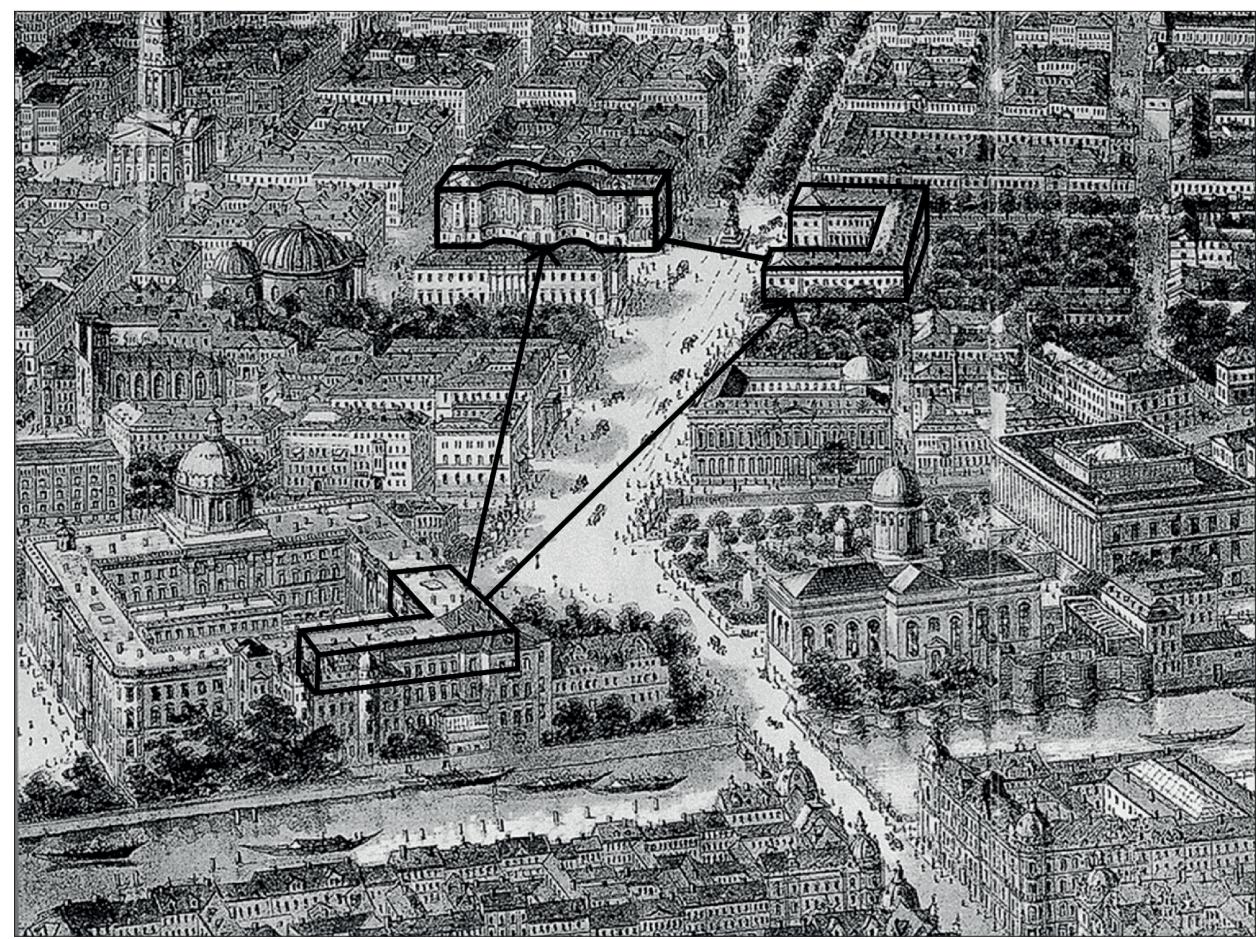

7. Adolf Eltzner, Panorama der deutschen Reichshauptstadt, 1886

sie von Beginn an ein Museum mit angeschlossenem Lehrbetrieb. Andere Universitäten hatten Universitätsmuseen, die Berliner Universität war ein lebendiges Museum. Dies hat ihre Sonderrolle bis heute ausgemacht. Als zweites Element der Geschichte des Schlosses ist festzuhalten, dass es über die Bestände der Kunstkammer als eines akademischen Weltmuseums zu einer Art Mutter der Berliner alma mater wurde.

\section{WELTKUNSTGESCHICHTE}

Nicht weniger bedeutsam als die naturkundlichen und medizinischen Sammlungen, die aus der Kunstkammer des Schlosses in die Universität überführt wurden, waren die außereuropäischen Sammlungen, welche dort zusammengekommen waren. Hierzu gehörten Objekte aus der berühmten Sammlung Forster. Reinhold Forster und dessen Sohn Georg, die auf der zweiten Weltumsegelung gemeinsam mit James Cook mitgesegelt waren, hatten eine Tausende an Stücken umfassende Sammlung von Naturalia und Arteficialia mitgebracht und nach ihrer Rückkehr im Jahr 1775 verschenkt 
oder verkauft. Das Berliner Interesse an diesen Objekten ist nicht verwunderlich, weil Georg Forster die deutsche Fassung seiner Reisebeschreibung, die ihn weltberühmt machte, im Jahr 1778 in Berlin publiziert hatte, aber andererseits war sein Name diskreditiert, weil er als glühender Anhänger der französischen Revolution nach Paris in das Exil gegangen war.

Nach der Eroberung Berlins durch die französischen Truppen im Jahr 1806 wurden neben den bedeutendsten Kunstwerken auch große Teile der Kunstkammer durch Dominique-Vivant Denon als Kriegsbeute requiriert und nach Paris überführt. Unter den Werken, die Denon in der Kunstkammer beschlagnahmen und nach Paris überführen ließ, befand sich auch die gesamte Sammlung außereuropäischer Werke, und diese blieben vollständig in Paris, wo sich jede Spur verloren hat. Umso intensiver wurde von den $\mathrm{Ku}-$ ratoren, Jean Henry und nach ihm Leopold Freiherr von Ledebur, in den folgenden Jahrzehnten der Wiederaufbau auch und gerade der ethnologischen Sammlung betrieben. Der Zuwachs an Exponaten machte es erforderlich, ein geographisch gegliedertes Inventarsystem einzuführen, welches mit der Einteilung in die Großräume China, Japan, die weiteren Gebiete Asiens, Afrika, Nordamerika, Südamerika und Australien mit der Südsee bis heute im Wesentlichen gilt. Was aus der historischen Distanz in seiner regionalen Zuordnung eine eher spannungsarme Kategorisierung darstellt, war zur Zeit seiner Formulierung ein Bekenntnis zur Diversität der Welt. Dem Konzept der Sprachtheorie Wilhelm von Humboldts vergleichbar, sollte die Gemeinschaft der Menschen nicht vertikal nach den Stufen ihrer damals angenommenen Entwicklung, sondern horizontal nach der regionalen und jeweils aus sich heraus zu verstehenden Kultur begriffen werden. Erst auf dieser Basis sollte das Gemeinsame definiert werden.

Eine besondere Rolle behielten Werke aus jener Sammlung, die von Vater Reinhold und Sohn Georg Forster anlässlich der zweiten Weltreise von James Cook zusammengestellt worden war. Namentlich wurde eine Reihe von Einträgen im Inventarbuch der Kunstkammer mit dem Namen Forster versehen. Mit aller Kraft versuchte die Leitung der Kunstkammer, Gebrauchsgegenstände aus diesen Sammlungen zu erwerben und diese gebührend herauszustellen, wie etwa tahitianische Keulen. Ein aus dem Jahr 1838 stammender Grundriss der Kunstkammer des Schlosses von Karl Friedrich Schinkel zeigt die nach Süden gehenden, gewaltigen Räume der "ethnographischen Sammlung", die einen Eindruck der hier versammelten Objektmengen vermitteln. Mit Blick auf diese ethnographische Sammlung des Schlosses hat Franz Kugler eine erste, veritable Weltkunstgeschichte verfasst, die jenem liberalen Geist, aus dem heraus sie entstanden war, in einer Kunstgeschichte aller Zeiten und Völker einlöste, und welche von den Steinartefakten der Vor- und 
Frühgeschichte bis in die Gegenwart reichte. Es handelt sich um die erste Universalgeschichte des Homo Faber. In seiner mit Blick auf die Kunstkammer des Berliner Schlosses geschriebenen, liberalen Weltkunstgeschichte vermeidet er die Zuspitzung auf die Gegenwart als der die Geschichte vollendenden und vollendet reflektierenden Instanz. In ihrer relativistischen Anlage bleibt sie ein Anspruch bis in unsere Zeit.

Als drittes Element von historischer Bedeutung ist festzuhalten, dass die ethnologischen Bestände der Kunstkammer des Schlosses jenes Anschauungsmaterial bot, angesichts dessen eine erste, liberale Kunstgeschichte der gesamten Welt von der Tiefenerschließung bis in die Artefakte der Steinzeit und der horizontalen Erfassung von Asien bis nach Amerika konzipiert und niedergeschrieben werden konnte.

\section{DIE MUSEUMSINSEL ALS FREISTA'TTE UND DAS TRAUMA VON 1848}

Der zu dieser Zeit herrschende Schlossherr, Friedrich Wilhelm IV., als dilettierender Kunsthistoriker und Zeichner ein dezidierter Förderer der Künste und Wissenschaften, formulierte den Plan, auf der Museumsinsel eine „Freistätte für Kunst und Wissenschaften“ zu errichten, welche die wissenschaftliche Forschung mit der kunsthistorischen, archäologischen und völkerkundlichen Präsenz der Artefakte verbinden sollte. Er hätte als einer der aufgeklärten, bildungsaffinen Monarchen der Nachwelt erhalten bleiben können, wenn er nicht gleichzeitig der romantischen Vorstellung einer tiefen Verbundenheit von Herrscher und Volk verfallen wäre, die im gemeinsamen christlichen Glauben ihren Ausdruck und ihre Erfüllung finden würde. Der Berliner Dom, wie ihn Schinkel konzipiert hatte, konnte dieser Verbindung von Nation und Religion aus der Sicht Friedrich Wilhelms IV. nicht genügen, und daher nahm er die Idee Andreas Schlüters auf, über dem Westportal des Schlosses eine Kuppel als weithin sichtbares Zeichen eines harmonischen Einklanges von Volk und Hof in der gemeinsamen Religion errichten zu lassen. Als Gegenmodell zum Vormärz, jener liberalen, demokratischen Bewegung, der auch Kugler anhing, wurde diese Kuppel jedoch zu einem Menetekel. 1848, im Jahr der europäischen Revolutionen, führten die inneren Spannungen auch in Berlin zu einem Aufstand, in dessen Verlauf, verursacht offenkundig durch einen Übertragungsfehler, zahlreiche Demonstranten erschossen wurden. In einer anonymen Darstellung ist das Geschehen festgehalten. Das Schloss zeigt die im Bau befindliche Kuppel, die in der kühnen Eisenkonstruktion eine Weite zu überspannen vermochte, die zu dieser Zeit 
eine Besonderheit war. Durch die historischen Ereignisse blieb jedoch allein der als repressiv empfundene Gehalt. Friedrich Wilhelm IV, der seine Truppen nach der Massenerschießung aus der Stadt entfernen ließ und sich damit selbst auslieferte, musste den aufgebahrten Toten die letzte Ehre erweisen.

Mit der Niederschlagung der Revolution von 1848 war das Ansehen des Schlosses als Sitz der Hohenzollern diskreditiert. Von diesem Moment an, und hierin liegt die vierte historische Dimension, hatte es seine repräsentative Funktion für die Hohenzollern auf Jahrzehnte verloren. Es erfüllte seine Aufgabe als Ort der Ämter und Geldinstitute weiterhin, aber seine ursprüngliche Funktion trat für mehr als eine Generation zurück.

\section{KAISERREICH UND REVOLUTION}

Erst mit der Reichseinigung im Jahr 1871 und der Thronbesteigung Kaiser Wilhelms II. nahm das Schloss im Gegenzug schließlich jene Funktion an, die ihm aus späterer Perspektive in Verkennung seiner bis dahin geprägten Bestimmung für seine gesamte Geschichte zugeschrieben wurde. Als zentraler Ort der des Herrscherhauses der Hohenzollern wurde es zum Symbol ihrer unheilvollen Herrschaft.

Als ein Menetekel gilt die sogenannte Kongo-Konferenz, auf der über die Aufteilung Afrikas in europäische Hoheitssphären entschieden wurde. Diese Versammlung hätte ebenso in Brüssel, London oder Paris stattfinden können, und in Berlin wurde sie nicht im Schloss, sondern im Reichskanzlerpalais in der Wilhelmstraße abgehalten, aber da ihr Abschlussdokument im Schloss besiegelt wurde, scheint es bis heute, als hätte es gleichsam als Akteur bei diesen fatalen Entscheidungen mitgewirkt. Unter Kaiser Wilhelm II. fand jene prekäre Steigerung seines Pathos statt, die das Schloss für die Militarisierung und die Stärkung imperialer Ansprüche des deutschen Kaiserreiches gleichsam verantwortlich machte. Der Sturz des Kaiserreiches fand folglich mit der Erstürmung des Berliner Schlosses statt. In einer der paradoxen Wendungen, zu der die dichterische Phantasie nicht ausreicht, wohl aber die Geschichte selbst, wurde ein markanter Bauteil des Schlosses zu einer Reliquie der kommunistischen Idee. Es handelt sich um das Portal IV, von dem aus der Führer der Kommunisten, Karl Liebknecht, der Legende zufolge die sozialistische Republik ausrief.

In der Weimarer Republik ging das Schloss vom Jahr 1920 an in seiner Gesamtheit in die öffentliche Hand über. Von besonderer Bedeutung war, dass auch die Universität in diesem Jahr in das Schloss Einzug hielt, um damit dem psychologischen Institut endlich Räume zur Verfügung stellen zu können, die groß genug waren, dass die Berliner Schule der Gestaltpsychologie 
ihre Forschungen durchführen konnten. Bis zur Emigration der weltberühmten Gestaltpsychologen Wolfgang Köhler, Max Wertheim und Rudolf Arnheim hat die Berliner Psychologie in den Räumen des Berliner Schlosses die Grundlage ihrer Geltung gelegt, und nach der Emigration wirkte sie vor allem in den Vereinigten Staaten nicht nur im Bereich des Design, sondern auch in der frühen Informatik mit Folgen weiter, die bis heute reichen.

Die erneute Verbindung zwischen Schloss und Forschung in der Weimarer Republik ist das fünfte Glied, das aus einer historischen Perspektive in der Kette der markantesten Ereignisse bestimmt werden kann.

\section{DIE ZERSTÖRUNG DES SCHLOSSES ALS DAMMONENAUSTREIBUNG}

Die Nationalsozialisten hatten angesichts ihrer Überzeugung, eine eigene Geschichte von Grund auf zu gestalten, trotz aller historischen Scheinlegitimität, die das Schloss etwa am Abend der Regierungsübernahme im Jahr 1933 durch Hitler bot, keine dezidierte Bestimmung für das Schloss.

In seinem Zentrum war Berlin fast vollständig ausgelöscht, aber wie durch ein Wunder war das Schloss selbst nicht in einem Ausmaß getroffen, dass es hätte abgerissen werden müssen. Vielmehr gab es Initiativen, es wieder in Stand zu setzen. In West wie Ost standen die Zeichen jedoch gegen jedwede Form der Restaurierung. Diese in immer neuen Varianten vorgebrachte Abscheu gegenüber jeder Form der Rekonstruktion erhielt eine geschichtspolitische Stoßrichtung. In einem maßgeblichen Manifest von Architekten aus dem Jahr 1947 hieß es programmatisch: „Das zerstörte Erbe darf nicht historisch rekonstruiert werden, es kann nur für neue Aufgaben und neue Formen entstehen." Rekonstruktionen wurde in diesem Moment unterstellt, die Erinnerung an die Zerstörungen, die von Deutschland ausgegangen waren, und die es selbst getroffen hatten, zu tilgen.

Die Ost-Berliner Parallele war die Sprengung des Schlosses (Abb. 8). Umso mehr sollte an die Gegenstimmen erinnert werden. Mein Vor-Vor-Vorgänger an der Humboldt-Universität, der Kunsthistoriker Richard Hamann, überreichte dem Ministerpräsidenten Otto Grotewohl im August 1950 ein entschiedenes Memorandum zur Beibehaltung des Schlosses: „Berlin ist arm an Denkmälern der Vergangenheit. Aber es besitzt ein Werk, das sich den größten der Vergangenheit würdig einreiht und in allen Kunstgeschichten der Welt genannt und abgebildet ist: das Berliner Schloss. Sein Schöpfer ist der größte Bildhauer und Architekt in Norddeutschland, Andreas Schlüter. In Ruinen steht es da: noch immer von einer faszinierenden Wucht und Monu- 


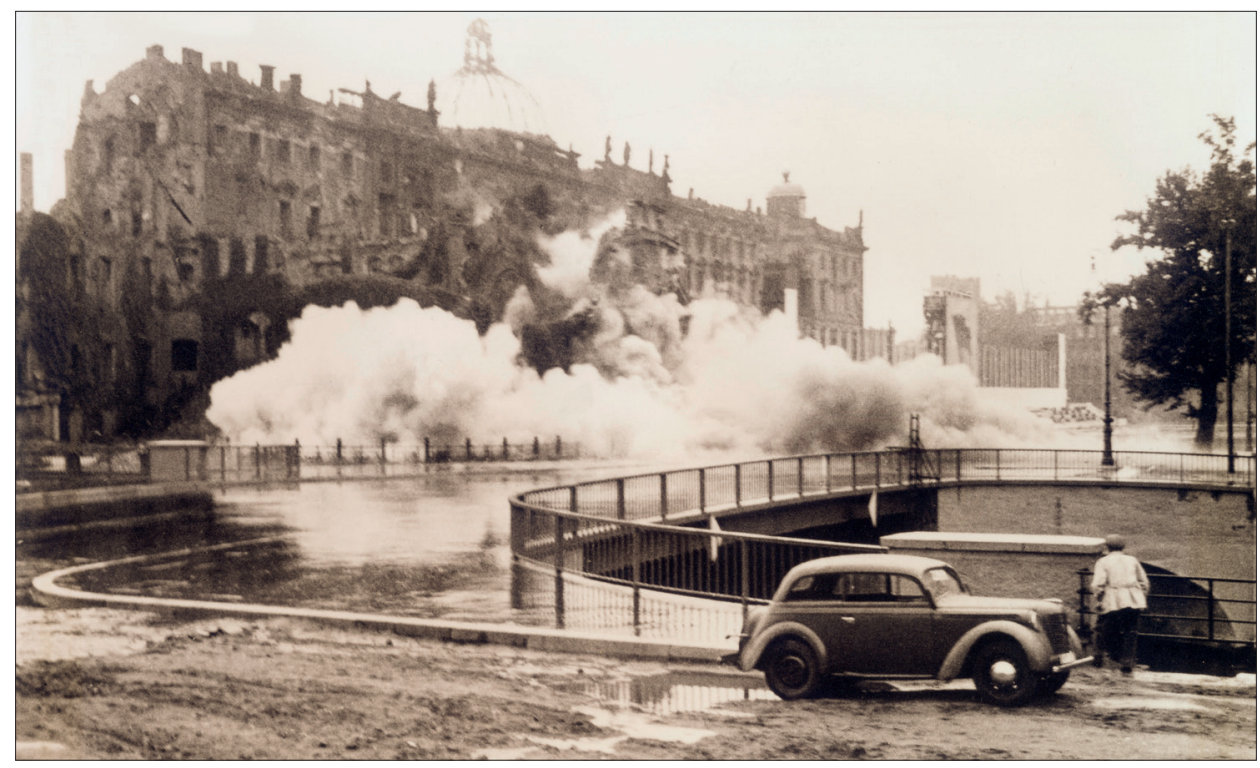

8. Sprengung des Schlosses, 1950

mentalität, ein Repräsentant des spezifisch norddeutschen Barock, der sich Michelangelos St. Peter in Rom, dem Louvre in Paris würdig zu Seite stellt." In diesen Zeilen wird deutlich, welche tiefe historische Identifikation gerade die Ruinenästhetik des Schlosses hervorrief. Es war durch Bomben schwer getroffen worden, ließ aber keinen Zweifel, dass es gerettet werden könne. Das Entsetzen über die Vorstellung, der Bau könne tatsächlich gesprengt werden, äußert sich in der Erklärung: „Alle Kunsthistoriker [...] macht der Gedanke an die Zerstörung des Schlosses und dieses historischen Zentrums Berlins krank." All diese Appelle waren jedoch fruchtlos.

Die sechste Etappe der Geschichte des Schlosses war sein zweifach erfolgtes Ende durch die Zerstörungen des Luftkrieges und den gezielten Abriss durch die Deutsche Demokratische Republik, die das Schloss als Gegenbild zu ihrer eigenen Bestimmung empfand. Die negative Bestimmung, mit der das Schloss im Jahr 1848 und dann wieder im Kaiserreich erfasst worden war, hatte zum ikonoklastischen Todesurteil seiner selbst geführt.

\section{DER PALAST DER REPUBLIK}

An die Stelle des Schlosses trat die Platzarchitektur der Aufmärsche, wie sie zum 1. Mai und zu anderen Anlässen auf dem Boden des ehemaligen Gebäudes durchgeführt wurden. Die Leere, die hierdurch entstand, war jedoch 
so unerträglich, dass die DDR entschied, auf dem Gelände des alten Schlosses einen Palast zu bauen, der die behutsame Modernisierung der Architektur der DDR bekräftigte (Abb. 9). Als „Palast der Republik“ hat er Architekturgeschichte geschrieben. In der DDR war er einerseits beliebt, weil er Angebote des Vergnügens und der Zusammenkunft bot, die in großem Umkreis sonst nicht zur Verfügung standen. Genau aus diesem Grund aber wurde er von Regimekritikern in geradezu gehasst.

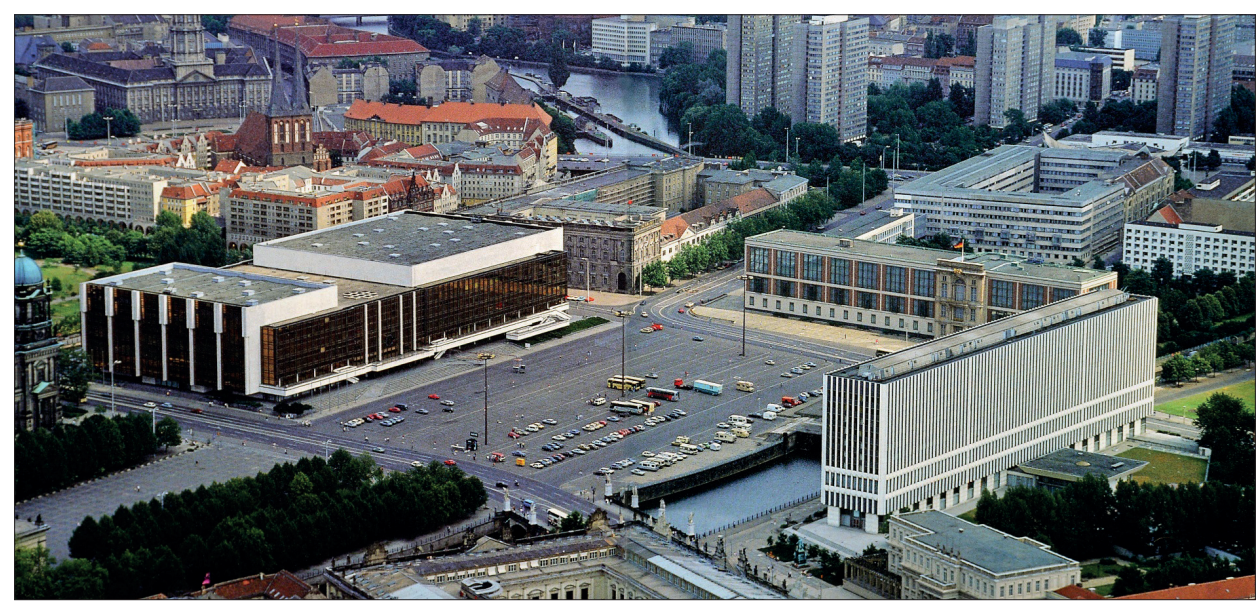

9. Luftbild des Ensembles um den Schlossplatz, 1990er Jahre

Nach der Wiedervereinigung Deutschlands im Jahr 1990 stand der Palast der Republik ebenso in der Diskussion wie das alte Berliner Schloss nach 1945. Als der Beschluss fiel, den Palast der Republik abzureißen, wurde als Grund ausgegeben, dass die Asbest-Verseuchung so hoch gewesen sei, dass ein Weiterbetrieb nicht möglich gewesen wäre, so dass eine Sanierung teurer kommen würde als ein Abriss. Mit dieser Begründung, aufgrund derer eine größere Zahl von Gebäuden hätte abgerissen werden müssen, wie zum Beispiel das Kongresszentrum in Westberlin, wurde der Anschein einer politischen Entscheidung zumindest rhetorisch vermieden. Tatsächlich aber war es offenkundig die nachhaltende Erschütterung über den Abriss des Berliner Schlosses, die dazu führte, dass der Palast der Republik wie eine Art Racheakt in einem langwierigen, schmerzlichen, von großartigen Performances begleiteten Prozess abgerissen wurde.

Aufbau und Abriss des Herzstïcks der DDR-Architektur waren als Epochenzeichen der realsozialistischen Republik und deren Ende das siebente Großereignis, das mit der Geschichte und Nachgeschichte des Berliner 


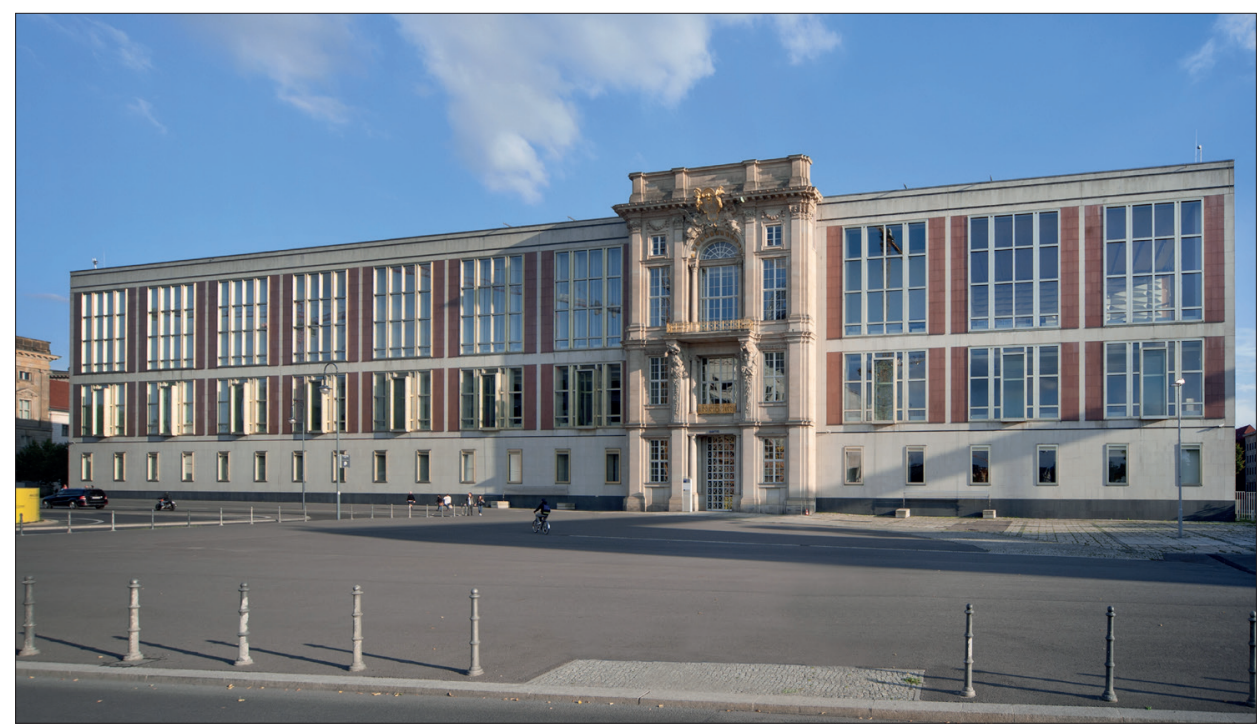

10. Staatsratsgebäude der DDR mit Portal IV des Stadtschlosses

Schlosses zu verbinden war. Es blieb allein das Portal IV, das als Baureliquie des Kommunismus vor dem Abriss des Schlosses im Jahr 1950 gerettet wurde, um in das im Jahr 1963 errichtete Staatsratsgebäude der DDR eingebaut zu werden (Abb. 10). Dieses Ensemble dürfte zu den surrealisten Gebilden gehören, welche die Architekturgeschichte insgesamt aufzuweisen hat.

\section{ENTSCHEIDUNG ZUM NEUAUFBAU}

Im Gegenzug entfaltete sich die Diskussion um die Rekonstruktion des abgerissenen Schlosses. Es gab Wettbewerbe mit außerordentlich fantasievollen Planungen, aber nachdem im Jahr 1993 das durch den Hamburger Verfechter der Rekonstruktion, Wilhelm von Boddien, errichtete 1:1 Modell einen bezwingenden Eindruck hinterlassen hatte, gab es zur Rekonstruktion zumindest der Außenhaut keine Alternative mehr. Damit jedoch war die Bestimmung des Inneren in keiner Weise entschieden. Im Jahr 2000 nahm die Expertenkommission "Historische Mitte Berlin“ die Arbeit auf, um über die inhaltliche Füllung des rekonstruierten Schlosses zu entscheiden. Ich selbst hatte nach meiner Berufung an die Humboldt-Universität im Jahr 1992 den Auftrag erhalten, die wissenschaftsgeschichtlichen Sammlungen der Universität zu erschließen und in einem Katalog zusammenzufassen. Der Ertrag dieser Untersuchungen, die ich gemeinsam mit dem Mathematiker Jochen 
Brüning unternahm, führte im Jahr 2000 zu einer Ausstellung im Berliner Gropius Bau unter dem Titel „Theater der Natur und Kunst". Sie spielte auf die Idee von Leibniz an, in die im Jahr 1700 gegründeten Akademie der Wissenschaften zu Berlin ein "Theatrum Naturae et Artis" zu inkorporieren. Der unerwartet großen Zahl von Besuchern konnte damit das ursprüngliche Ensemble der Universitätssammlungen präsentiert werden. In den Ausstellungsräumen fanden permanent Lehrveranstaltungen und Diskussionen statt, so dass sie sich mit der akademischen Lehre verzahnten.

Vor diesem Hintergrund habe ich im Jahr 2001 vor der Kommission „Historische Mitte Berlin“ das Konzept vorgestellt, die Sammlungen der Universität und damit das Rückgrat ihres Erfolges, als gedankliches Konzept gleichsam in das Schloss zurückzuspulen und die alte Verbindung zwischen Schloss und Universität wieder aufzunehmen. Im selben Atemzug vertraten Klaus Lehmann als Präsident und Peter Klaus Schuster als Museumsleiter der Stiftung Preußischer Kulturbesitz die Idee, die außereuropäischen Sammlungen in das Schloss wieder zurückzugeben und damit einen Teil der dort ehemals befindlichen Sammlung zur groben Bestimmung des rekonstruierten Gebäudes zu machen. Die Kommission beschloss, die Konzepte der Stiftung preußischer Kulturbesitz und der Universität anzunehmen und beide Körperschaften als Akteure des Humboldtforums zu bestimmen. Als dritter Akteur kam Berlin hinzu, das mit seiner Stadtbibliothek ebenfalls Einzug in das Schloss halten sollte, um ein lebendiges Klima zu erzeugen, für welches das Pariser Centre Pompidou eine Art Vorbild war. Im folgenden Jahr, 2002, wurde das Konzept nach einer durchweg positiven Diskussion durch den Deutschen Bundestag bestätigt. Die Grundidee, Sammlungen, die sich im Rahmen der Kunstkammer einmal im Schloss befunden hatten, zum Anlass zu nehmen, um deren Ansprüche unter den veränderten Umständen der Gegenwart neu wirken zu lassen, hatte gestochen. Der Beifall in der Öffentlichkeit war beträchtlich, und nach diesem so positiven Beginn hätte es eine zügige Durchführung geben können. Die folgende Wirtschaftskrise, welche die ersten Jahre des neuen Jahrhunderts beeinträchtigte, ließ es jedoch als unangemessen erscheinen, angesichts von mehr als 5 Millionen Arbeitslosen ein Schloss der Hohenzollern mit beträchtlichen Mitteln aus dem öffentlichen Haushalt zu rekonstruieren. Das Projekt sollte ausgesetzt, wenn nicht aufgegeben werden. Die Prozesse, die in den Ministerien begonnen hatten, konnten jedoch nicht von einem Tag auf den anderen aufgehalten werden, weil längst Verträge geschlossen waren, die ein Weiterarbeiten erforderten. Und so kam es dazu, dass das Projekt der Wiedererrichtung des Schlosses unter der Oberfläche der öffentlichen Wahrnehmung weitergeführt wurde, obwohl es offiziell auf Eis 
gelegt worden war. Dies begründete, dass wie aus dem Nichts im Dezember 2007 der Wettbewerb für die Gestaltung des Schlosses ausgelobt und eine Kommission zur Entscheidung über dessen Form eingesetzt wurde, welche die Grundregel, dass die äußere Fassade in ihrer historischen Gestalt unangetastet sein sollte, unabdingbar verteidigen würde. Als achtes Ereignis tritt erstmals die Rekonstruktion des nicht mehr existenten Schlosses in Erscheinung. Damit beginnt jene Geschichte, die Ende des Jahres 2019 ihren Abschluss finden soll.

\section{DER NEUBAU}

Aus dem Wettbewerb ging das Projekt des italienischen Architekten Franco Stella erfolgreich hervor. Erneut war es eine italienische Tradition, die dem Berliner Schloss das Gepräge gab, nachdem Andreas Schlüter um 1700 italienische Formen des 16. und 17. Jahrhunderts auf eine höchst subtile Weise plastisch zusammengeführt hatte. Nun war es der Rekurs auf den italienischen Rationalismus, der die Form mitbestimmte.

Stella entstammt jener Tradition der Architekturgeschichte des 20. Jahrhunderts, die als italienischer Rationalismus nach dem Ersten Weltkrieg entstand, um dem antihistorischen Elan der Futuristen eine Moderne entgegenzusetzen, die insbesondere an die Baulehre der Antike anknüpfte, um deren Architekturformen durch radikale Reduktionen auf einen mathematischen Kern zu reduzieren. Die Gestaltung lebt vom Wechselspiel zwischen vollständig geschlossener Wand und starker Durchgliederung, wie sie der führende Kopf Giuseppe Terragni in immer neuen Varianten vorgeführt hat. Stella selbst hat dieses Prinzip mehrfach angewendet, so etwa im Komplex seiner Schule in Orgiano. Die Grundregel des italienischen Rationalismus, alle Formen auf den Prinzipien der mathematischen Ratio, der Proportion und der Klarheit aufzubauen, bestimmten Stellas Weigerung, den Bau Schlüters mit seinen neu konzipierten Partien zu durchstecken. Beide stehen hart gegeneinander, um in dieser Konfrontation deutlicher zusammenzuspielen, als es eine Vermischung der beiden Stile erlaubt hätte. In geradezu schroffer Klarheit entwickelt sich dieses Prinzip im östlichen Flügel des Schlosses, der zur Spreeseite hin als ein kraftvoller Riegel seiner Selbst inszeniert ist. Auch wo der Neubau mit der Rekonstruktion der historischen Fassaden an den Seiten im Norden und Süden aufeinandertrifft, entsteht keine romantische Berührung. Vielmehr erweckten dieser Stelle eingesetzte Rücksprung den Eindruck, dass der Ostriegel vor dem eigentlichen Bau mit einem gehörigen Abstand aufragt. 
Stellas Wandgestaltung zieht sich durch den gesamten Bau. Es ist ein Coup, dass die Westseite des Schlüter-Innenhofes als eine wiederholende Variation der Fassade des Ostriegels nochmals aufgeführt wird. Auf diese Weise gelingt eine Harmonie aus der Differenz (Abb. 11). Der Kontrast zwischen dem glatt polierten Stein von Stellas Baukörper und der historischen Innenfassade Schlüters bewirkt eine eigene, sich wechselseitig öffnende Komplexität.

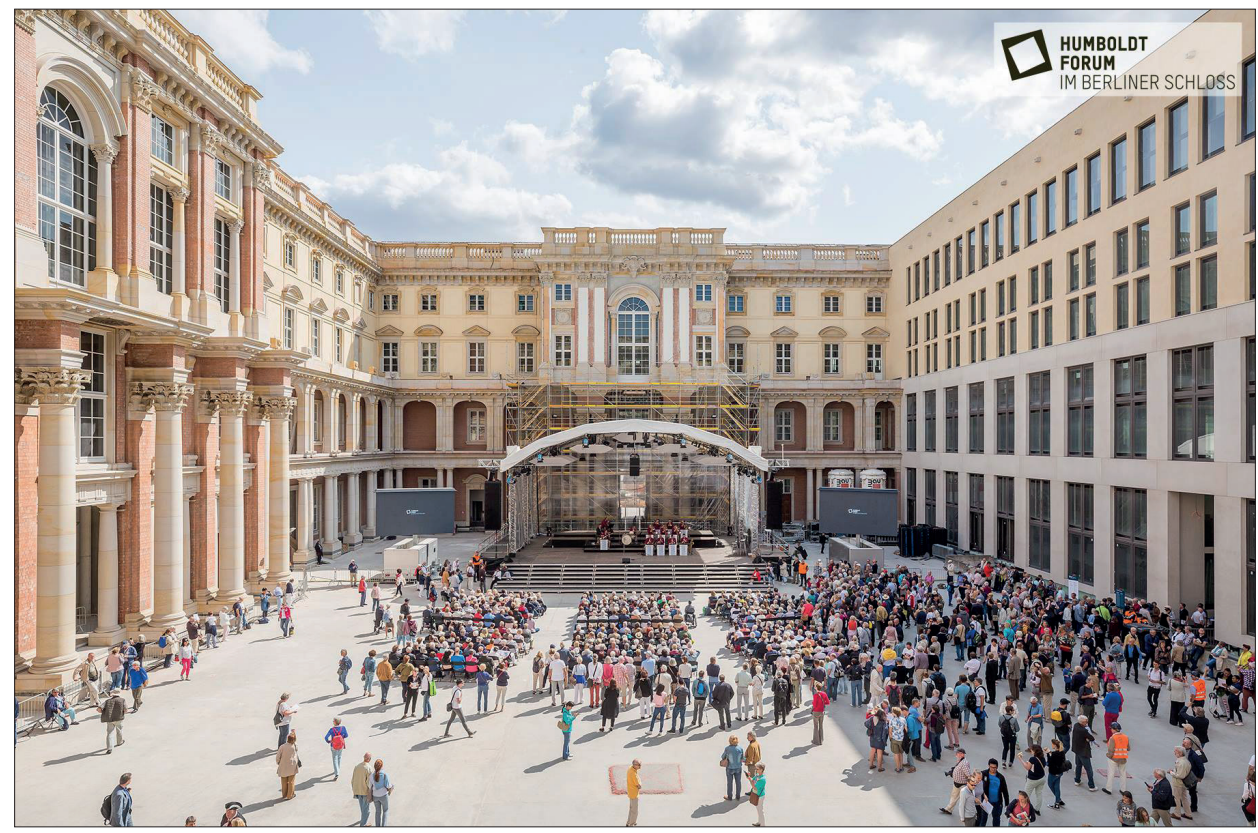

11. David von Becker, Schlüterhof des Berliner Stadtschlosses, 2018

Im Juni des letzten Jahres hatte das neu errichtete Eosander-Tor erstmals Premiere als Veranstaltungsort (Abb. 12). Es gab ein Programm an zwei Tagen, das knapp 40.000 Menschen anlockte. Es war ein wirklich erhebender Moment, zu sehen, wie das Portal und dessen Skulpturen gleichsam als eigener Akteur in dem minimalistischen Ambiente funktionierte. Die Famae der Bogenzwickel sind großartige Reproduktionen, in die wunderbarer Weise ein Teilstück als Spolien eingesetzt werden konnte. Die Rekonstruktion bekämpft die Topik dieser Wiederaufführung eines antiken Triumphbogens, indem der dargestellte Sieg sich selbst ein Trümmer ist. Sie ist eingestellt wie ein Requisit, wie eine Theaterdekoration in einem größeren, modernen Ambiente. Beide Pole wirken aufeinander und gegeneinander. Die riesige Eingangshalle ist von einer surrealen Spannung zwischen römischem Kolo- 


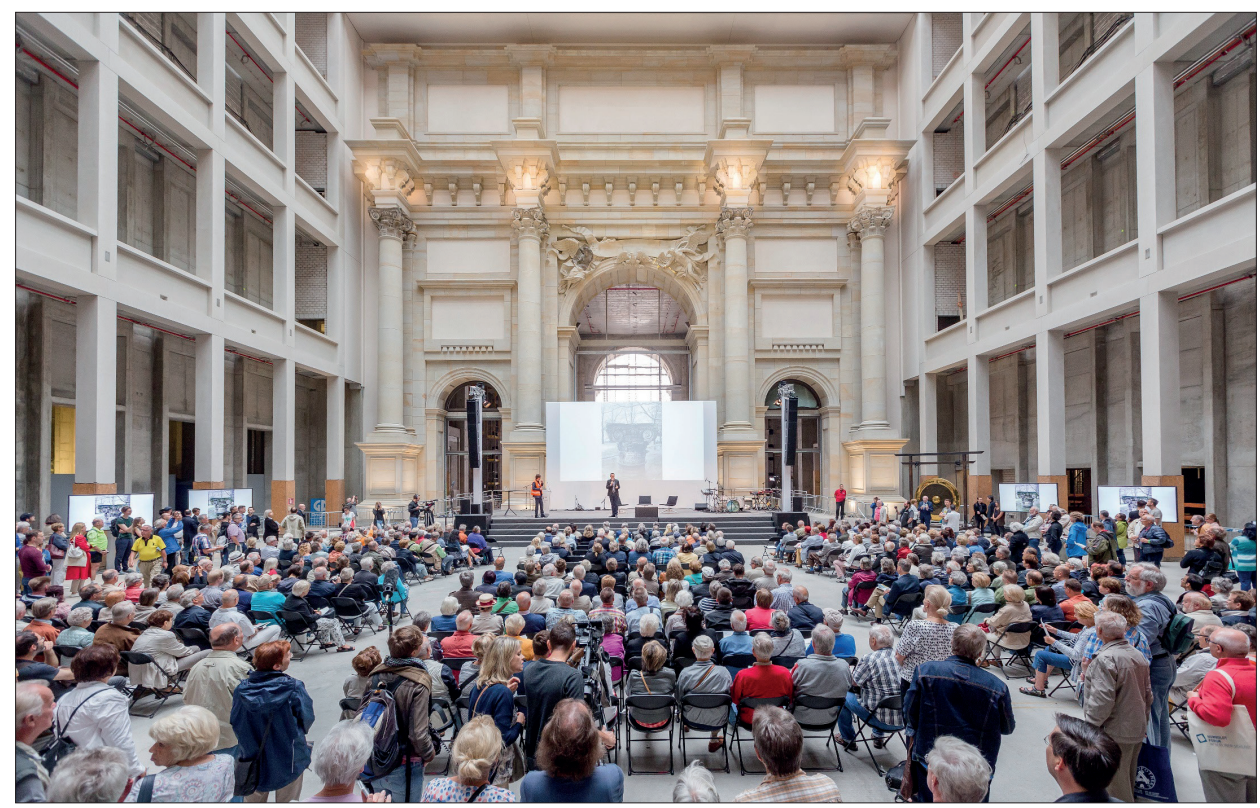

12. Berliner Stadtschloss, Atrium mit Rekonstruktion des Eosanderportals, 2018

ssalbau und italienischem Rationalismus bestimmt. Von einer der Galerien kann auf das Eosander-Tor und das Atrium geblickt werden. Der Blick geht auf Originalkapitelle, die ihrerseits den antiken Septimus-Severus-Bogen rekonstruktiv von Rom nach Berlin verfrachten. Darüber und darunter dann die heutigen Rekonstruktionen. Historisch wie aktuell reflektiert das Berliner Schloss eine Italianità, die allen Vorstellungen eines hier inkorporierten restaurativen oder gar militaristischen Inhalts fundamental widerspricht. Vor allem ist es Stellas Vermögen, dem Gebäude eine urbanistische Qualität zu geben, in dem Tag und Nacht geöffnete Straßen durch das riesige Areal geführt werden sollen, welche die Kommission bestachen.

Das neunte Element der historischen Ereignisse betrifft die Wiederkehr jener Italianità der Schlossarchitektur, die von Andreas Schlüter begründet wurde. Nun ist es der italienische Rationalismus, der den Eindruck des Humboldt Forums von Osten und in seinem Inneren bestimmt.

\section{GESCHICHTE UND GEGENWART}

Je deutlicher sich die Formen der Rekonstruktion abzeichneten, desto stärker äußerte sich eine Kritik, die von Beginn an gegen die Rekonstruktion gewesen war, weil sie den Geist der Hohenzollern und damit einen zutiefst 
reaktionäres Denken neu aufführen und einen neuen Stimulus geben würde. Diskussionen, die seit der Scheinerrichtung der Fassade im Jahr 1993 erledigt schienen, kamen und kommen mit einer Vehemenz zurück, die das Gebäude auch nach seiner Vollendung begleiten dürften. Der Grund liegt darin, dass die Bundesrepublik Deutschland trotz der Wiedervereinigung eine positiv bestimmte Alternative zur Betrachtung der deutschen Geschichte bislang nicht entwickeln konnte. Die Problematik liegt darin, dass alles, was eine positiv bestimmte Zielvorstellung entwickelt, unwillkürlich mit dem Verdacht verbunden wird, die Erinnerung an das Grauen der Jahre nach 1933 zu verkleinern. Die Raison d'Etre der Bundesrepublik Deutschland hat seit ihrer Gründung in großen Zügen darin bestanden, nie wieder etwas zuzulassen, was dem Nationalsozialismus gleichkäme. Ihre Legitimität besteht bis heute in der Verneinung der Naziherrschaft. Die Bedingung des deutschen Gemeinwesens ist die Reflexion ihrer schuldbeladenen Geschichte. Vor diesem Hintergrund entstand im Jahr 2000 die Grundidee, im Zentrum der Hauptstadt eines Landes, das 1939 große Teile der Welt in den Abgrund gestürzt hatte, einen Raum zu schaffen, in dem die Artefakte der unterschiedlichsten Kulturen des gesamten Globus zusammenkommen sollten, um gemeinsam mit den vorderasiatischen und den europäischen Sammlungen der Museumsinsel ein Ensemble zu bieten. Dem Wort des großen Ethnologen Claude Lévi Strauss gemäß sollte es zeigen, was die Menschen in der letzten Konsequenz miteinander verbindet und nicht etwa in Zerstörungen und Verwüstungen führt. Die Umkehrung dieser Position in die Anmaßung, von europäischen, und im besonderen deutschen, und damit per se schuldbeladenen Kategorien her die Welt zu ordnen, ist für meinen Begriff verstörend, denn sie bekräftigt, wogegen sie argumentiert. Vor dem Hintergrund dessen, was ich Ihnen in diesen zehn Schritten zu skizzieren versucht habe, mag es verständlich werden, warum ich es nach wie vor für eine Pflicht halte, an eine Tradition anzuknüpfen, die von Leibniz, Georg Forster und den Brüdern Humboldt begründet wurde.

Das Berliner Schloss steht seit seiner Errichtung im Jahr 1700 in immer neuen Rahmenstellungen paradigmatisch für die Wellenschläge der Diskussion einer solchen Orientierung. Gebaut im Sinne einer Italianisierung des preußischen Zentrums, keinesfalls ein Gebilde repräsentativer Macht, sondern ein Gefäß der gesellschaftlichen Bindung, eher ein Leviathan als eine Krone, Ort einer mikrokosmischen Zusammenziehung der Welt in der Kunstkammer unter unhierarchischen Gesichtspunkten, Mutter der Alma Mater Berlins, Ort der 1848er Revolution und Stätte der Demütigung des preußischen Königs, im Gegenzug Propagandastätte des Weltmachtanspruches der Hohenzollern im Kaiserreich, dann Ort einer republikanischen In- 
besitznahme seitens der Weimarer Republik, zerstört als Symbol des preußischen Militarismus, und im Gegenzug wiedererrichtet im Kompromiss einer authentischen Außenfassade und einem modernen Innenleben, um die traditionellen Nutznießer, die Universität und die außereuropäischen Sammlungen sowie Berlin als programmatische Gestalter aufzunehmen, und schließlich erbittert umkämpft als Medium einer universalen Orientierung oder, diametral entgegengesetzt, als reaktionäre Wiederaufführung eines verwerflichen Historismus, kann das Berliner Schloss als eine Art Psychogramm der unterschiedlichen Stadien der deutschen Befindlichkeit erachtet werden.

All dies ist so paradox wie das Leben selbst, wenn Sie mir diesen Allgemeinplatz erlauben. Aber ich komme zu keinem anderen Schluss. Zwischen der Zerstörung und der Hoffnung auf ein gemeinschaftliches Zusammenleben, das sich jeweils weitaus reichere Horizonte vorstellte, als es die örtlichen Gegebenheiten zu bieten vermochten, hat sich das Schicksal des Berliner Schlosses abgespielt, und es wird es weiterhin tun. In seiner äußeren Gestalt eines der eindrucksvollsten Gebilde des europäischen Barocks, bleibt es aufgrund seiner Geschichte eine Projektion für unterschiedliche Orientierungen. Wenn es dies bewahren sollte, ohne dass eine weitere Geschichte ähnlich dramatische Umbrüche zu verzeichnen hätte, wie sie das neu errichtete Schloss inkorporiert, dann hätte das Humboldt Forum seinen Zweck erfüllt.

\section{SCHLUSS}

Damit komme ich zum Ende. Der Grund, warum ich neben dem Gesagten nicht ohne innere Beteiligung vor Sie getreten bin, liegt in zwei Bildern (Abb. 13). Bei dem ersten handelt es sich um eine Fotoaufnahme, die sich im Nachlass meines Vaters befand. Sie stammt aus der Zeit, in der das Posener Institut gegründet wurde. Sie zeigt meinen Vater auf einem Schaukelpferd, das als Staffage in einem Fotoatelier zur Verfügung stand. Der Rückseite ist der Name dieser Einrichtung zu entnehmen. Die Eltern meines Vaters lebten in Posen, und daher entstand diese Aufnahme in jenem "Atelier Apollo" aus der Wilhelmstraße, heute Marcinkowski-Alleen, und wenn wir uns heute im Wilhelmsschloss befinden, dem Kulturpalast, dann ist dieser lose Zusammenhang gegeben. Adam Labuda, mit dem gemeinsam ich glückliche Jahre an der Humboldt-Universität zu Berlin verbringen konnte, ist mit mir fast gleichalt. Wenn es nicht das Grauen des Überfalls auf Polen mit all seinen Folgen gegeben hätte, wären Adam Labuda und ich möglicherweise in derselben Klasse im Gymnasium von Posen gewesen, und wir hätten uns viel früher befreundet, als dies dann noch vor dem Fall der Mauer geschah. 

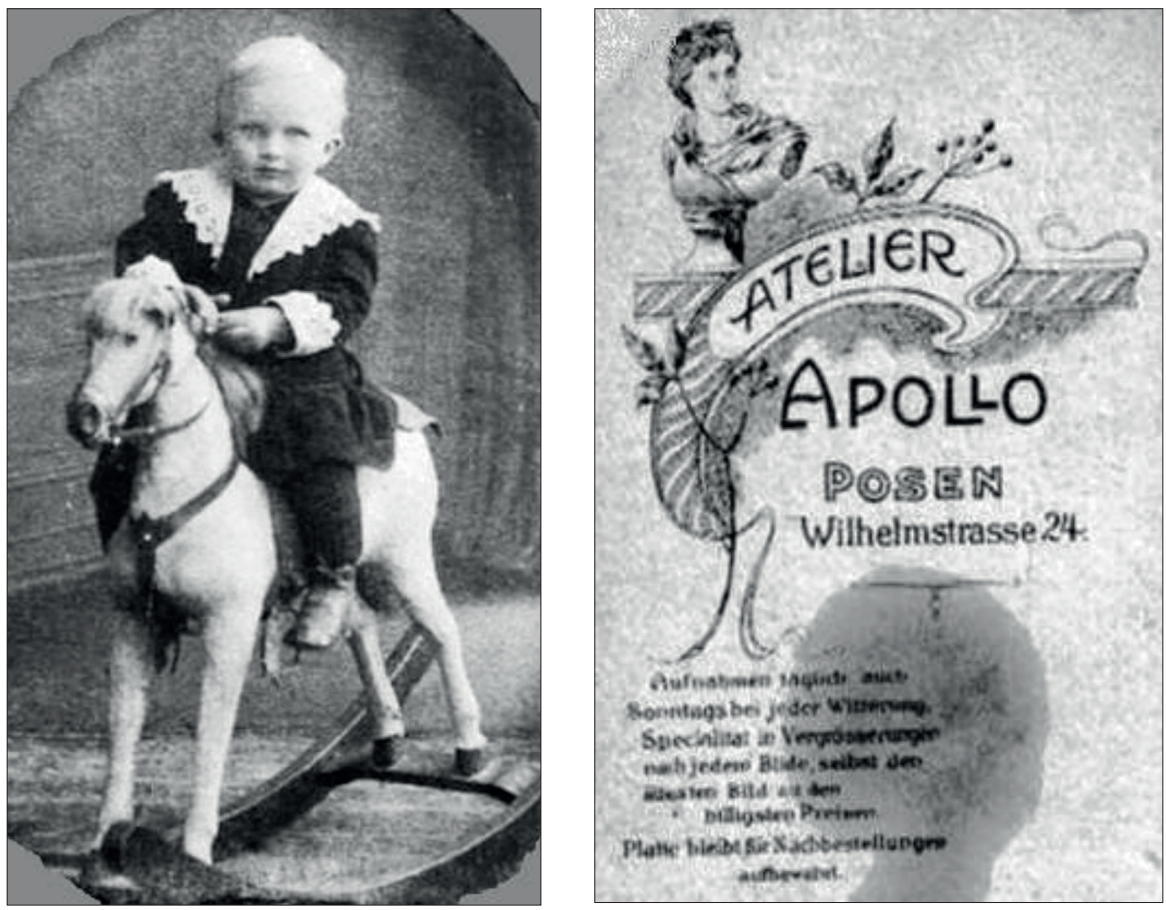

13. Gerhard Bredekamp, Fotografie, Atelier Apollo, Posen, ca. 1919

Sehr geehrte Damen und Herren, Sie mögen, das ist meine Hoffnung, nachempfinden können, warum es mir ein besonderes Anliegen war, vor Ihnen, in Posen, über ein Drama der Geschichte zu sprechen, das sich mit dem Berliner Schloss verbindet, dem ersten Großauftrag des polnischen Hofkünstlers Schlüter. Ich hoffe, vermittelt zu haben, dass es lohnt, im gebrochenen Anspruch seiner architektonischen Gestalt und im Ansatz seiner Kunstkammer verteidigt und gefüllt zu werden.

Meine Damen und Herren, den kommenden 100 Jahren des Posener Institutes wünsche ich eine Fortsetzung des glorreichen ersten Jahrhunderts! Ich bedanke mich für Ihre Aufmerksamkeit.

\section{BIBLIOGRAPHIE}

Andreas Schlüter und das barocke Berlin, Ausstellungskatalog, Hg. H.-U. Kessler, Berlin und München 2014

Bernau N., Von der Kunstkammer zum Musenarchipel. Die Berliner Museumslandschaft 1830-1994, in: Museumsinszenierungen. Zur Geschichte der Institution des Kunstmuseums. Die Berliner Museumslandschaft 1830-1990, Hg. 
A. Joachimidis, S. Kuhrau, V. Vahrson und N. Bernau, Dresden und Basel 1995, S. $15-35$

Boddien, W. von, Fassade. Der Palast der Republik hat sich überlebt, in: Volkspalast. Zwischen Aktivismus und Kunst, Hg. A. Deuflhardt, S. Krempel-Klieeisen, M. Linienthal, H. Müller, Ph. Oswalt, Recherchen 30, 26.08.2008, S. 249-252

Bolz P., From Ethnographic Curiosities to the Royal Museum of Ethnology. Early Ethnological Collections in Berlin, in: Adolf Bastian and his Universal Archive of Humanity. The Origins of German Anthropology, Hg. M. Fischer, P. Bolz und S. Kamel, Hildesheim, Zürich und New York 2007, S. 173-190

Bredekamp H., Der lange Atem der Kunstkammer: Das Neue Museum als Avantgarde der Vorvergangenheit, in: Museale Spezialisierung und Nationalisierung ab 1830. Das Neue Museum in Berlin im internationalen Kontext, Hg. E. Bergvelt, D. Meijers, L. Tibbe, E. van Wezel, Berlin 2011, Berliner Schriftenreihe zur Museumsforschung, Bd. 29, S. 25-36

Bredekamp H., Das Schloss und die Universität: eine nicht endende Beziehung, in: Das Humboldt Forum. Die Wiedergewinnung der Idee, Hg. H. Bredekamp und P.-K. Schuster, Berlin 2016, S. 104-133

Bredekamp H., Berlin am Mittelmeer. Kleine Architekturgeschichte der Sehnsucht nach dem Süden, Berlin 2018

Bredekamp H., Aby Warburg, der Indianer. Berliner Erkundungen einer liberalen Ethnologie, Berlin 2019

Bredekamp H. und E. Dolezel, Die Berliner Kunstkammer und die Utopie von Tangermünde, in: Cranach und die Kunst der Renaissance unter den Hohenzollern. Kirche, Hof und Stadtkultur, Ausstellungskatalog, Berlin 2009, S. 137-141

Bredekamp H. und M. Eissenhauer, Keimzelle Kunstkammer, in: Das Humboldt-Forum im Berliner Schloss. Planungen. Prozesse. Perspektiven, München 2013, S. $50-57$

Buddensieg T., Berliner Labyrinth. Preußische Raster, Berlin 1993

Dieckmann F., Von Schlüter zu Stella oder: Die Fehler des Politbüros, in: Das Humboldt Forum. Die Wiedergewinnung der Idee, Hg. H. Bredekamp und P.-K. Schuster, Berlin 2016, S. 20-36

Dolezel E., „Lehrreiche Unterhaltung" oder "Wissenschaftliche Hülfsmittel"? Die Berliner Kunstkammer um 1800. Eine Sammlung am Schnittpunkt zweier musealer Konzepte, „Jahrbuch der Berliner Museen“ 2004, N.F., 46, S. 147-160

Dolelzel E., Der Traum vom Museum. Die Berliner Kunstkammer unter Jean Henry (1794-1805) und das Akademiemuseum des 18. Jahrhunderts, Berlin 2019

Franz Theodor Kugler. Deutscher Kunsthistoriker und Berliner Dichter, Hg. M. Espagne, B. Savoy, C. Trautmann-Walter, Berlin 2010

Geyer A., Geschichte des Schlosses zu Berlin, Bd. 1: Die kurfürstliche Zeit bis zum Jahre 1698, Textband und Bildband, Berlin 1993

Goldenbaum L., Ein Schloss in Erwartung kollektiver Sinnstiftung, in: Das Humboldt Forum. Die Wiedergewinnung der Idee, Hg. H. Bredekamp und P.-K. Schuster, Berlin 2016, S. 148-189

Hinterkeuser G., Das Berliner Schloss. Der Umbau durch Abdreas Schlüter, Berlin 2003 
Hinterkeuser G., Das Berliner Schloss. Die erhaltene Innenausstattung. Gemälde, Skulpturen, dekorative Kunst, Regensburg 2012, S. 100-107

Holland A., Johann Friedrich Eosander genannt von Göthe (1669-1728). Anmerkungen zu Karriere und Werk des Architekten, Ingenieurs und Hofmannes am Hof Friedrichs I. in Preußen, Weimar 2002

Humboldt Forum. Der lange Weg 1999-2012, Hg. V. König und A. Scholz, Berlin 2011, Reihe: Baessler-Archiv. Beiträge zur Völkerkunde, Bd. 59

Das Humboldt Forum. Die Wiedergewinnung der Idee, Hg. H. Bredekamp und P.-K. Schuster, Berlin 2016

Kugler F.Th., Handbuch der Kunstgeschichte, Bd. 1-2, Stuttgart 1842

Peschken G., Hans-Werner Klünner unter Mitarbeit von Fritz-Eugen Keller und Thilo Eggeling, Das Berliner Schloß, Frankfurt am Main, Wien und Berlin 1982

Pratschke M., Gestaltexperimente unterm Bilderhimmel. Das Psychologische Institut im Berliner Stadtschloss und die Avantgarde, Basel 2016

Stella F., Ausgewählte Schriften und Entwürfe (= Franco Stella, Bd. 1), Berlin 2010

Stephan P., Das Humboldt-Forum als moderner Weiterbau des Berliner Schlosses (= Franco Stella, Bd. 2), Berlin 2010

Theater der Natur und Kunst. Theatrum Naturae et Artis. Wunderkammern des Wissens, Katalogband und Essayband, Hg. H. Bredekamp, J. Brüning und C. Weber, Berlin 2000

Theuerkauff Ch., Zur Geschichte der Brandenburgisch-Preußischen Kunstkammer bis gegen 1800, in: Die Brandenburgisch-Preußische Kunstkammer, Ausstellungskatalog, Berlin 1981, S. 13-34

Vermeulen H.F., Before Boas. The Genesis of Ethnography and Ethnology in the German Enlightenment, Lincoln und London 2015

Wezel E. van, Die Konzeptionen des Alten und Neuen Museums zu Berlin und das sich wandelnde historische Bewußtsein, "Jahrbuch der Berliner Museen" 2001, 43, Beiheft, Berlin 2003, S. 114-117

Horst Bredekamp

Humboldt-Universität, Berlin

FROM THE BERLIN PALACE TO HUMBOLDT FORUM. A PARADIGM OF CONFLICT IN GERMAN HISTORY

\section{Summary}

The lecture concerns the Berlin Palace (Stadtschloss) and presents a view of its long history, starting with its construction in the Baroque style by an artist of the Polish origin, Andreas Schlüter, up to its contemporary reconstruction with a new institutional function (Humboldt Forum). The ten sections of the text not only present architectural and artistic history of this residence but also pivotal historical events and contexts which affected the dimensions and meaning of its functioning. The Palace, entangled 
into German history but also reflecting it, especially as regards the $19^{\text {th }}$ and $20^{\text {th }}$ centuries, becomes both a starting point for an evaluation of this history and posing questions about the future. Along with the ferociously debated, present-day reconstruction and its museum function, it also seems to be a psychogram of diverse stages of the condition of German spirit.

Keywords:

Berlin, Humboldt Forum, residential architecture, architecture and power, kunstkammer, university 